\title{
BMJ Open Effectiveness of the Gold Standard Programme (GSP) for smoking cessation on smokers with and without a severe mental disorder: a Danish cohort study
}

\author{
Mette Rasmussen, ${ }^{1}$ Mads Klinge, ${ }^{1}$ Jesper Krogh, ${ }^{2}$ Merete Nordentoft, ${ }^{2}$ \\ Hanne Tønnesen ${ }^{1,3,4}$
}

To cite: Rasmussen $\mathrm{M}$, Klinge M, Krogh J, et al. Effectiveness of the Gold Standard Programme (GSP) for smoking cessation on smokers with and without a severe mental disorder: a Danish cohort study. BMJ Open 2018;8:e21114. doi:10.1136/ bmjopen-2017-021114

- Prepublication history and additional material for this paper are available online. To view these files, please visit the journal online (http://dx.doi org/10.1136/bmjopen-2017021114).

Received 12 December 2017 Revised 5 March 2018 Accepted 15 May 2018

Check for updates

${ }^{1}$ Clinical Health Promotion Centre, Bispebjerg and Frederiksberg Hospital, Copenhagen, Denmark ${ }^{2}$ Mental Health Centre Copenhagen, Copenhagen University Hospital, Hellerup, Denmark

${ }^{3}$ Health Science, University of Southern Denmark, Odense, Denmark

${ }^{4}$ Clinical Health Promotion Centre, Department of Health Sciences, Lund University, Lund, Sweden

Correspondence to

Mette Rasmussen;

mette.rasmussen.03@regionh. $\mathrm{dk}$

\section{ABSTRACT}

Objectives We compared the effectiveness of an intensive smoking cessation intervention among smokers with and without a severe mental disorder (SMD) and identified factors associated with successful quitting. The main hypothesis was that smokers with an SMD would be less likely to stay continuously smoke-free for 6 months.

Design A prospective cohort study.

Setting In all, 302 smoking cessation clinics in Denmark from municipal clinics, pharmacies, hospitals, midwives, primary care facilities and other private providers who reported data to the national Danish Smoking Cessation Database from 2006 to 2016 participated in this study. Participants A total of 38293 patients from the Danish Smoking Cessation Database. Patients with an SMD were identified by linking data to the Danish National Patient Register. Diagnoses of organic mental disorders (F0 chapter) or intellectual disabilities (F7 chapter) were not included. Smokers $\geq 18$ years old who were attending a Gold Standard Programme (GSP) with planned followup were included. Smokers not wanting contact after 6 months were excluded.

Interventions A comprehensive manual-based smoking cessation intervention comprising five meetings over a 6-week period (the GSP).

Main outcome measures Self-reported continuous abstinence at the 6-month follow-up.

Results In all, $69 \%$ of the participants participated in the follow-up after 6 months. The overall rate of successful quitting was high but significantly lower in SMD smokers (29\% vs $38 \%$; OR $0.74 ; 95 \%$ Cl 0.68 to 0.80). Variables associated with successful quitting were compliance (defined as attending $\geq 75 \%$ of the planned meetings), older age and male gender as well as not being disadvantaged, heavy smoking or recommendation of intervention by health professionals.

Conclusions Only $29 \%$ of smokers with an SMD successfully quit smoking which was significantly lower than the $38 \%$ of smokers without an SMD. Compliance was the most important predictor for successful quitting.

\section{INTRODUCTION}

The prevalence of smoking among patients with mental illness is relatively high. ${ }^{2} \mathrm{~A}$ Danish survey showed that $39 \%$ of patients
Strengths and limitations of this study

- This was a prospective cohort study based on 38293 smokers with or without mental disorder(s).

- Quit rates at the 6-month follow-up were based on unvalidated self-reporting.

When identifying smokers with psychiatric issues in this study, only smokers with a mental disorder severe enough to justify hospitalisation (inpatient or outpatient) were recognised. This cohort might contain patients with less severe mental disor$\operatorname{der}(\mathrm{s})$ (SMD/SMDs), who (in this study) were categorised as smokers without SMD.

- Participants with an SMD were included independent of the time span from diagnoses to intervention onset.

- This study was based on routinely collected health data, but because the aim of this study was in line with the purposes of the Smoking Cessation Database, we considered the implications minimal.

with a mental illness were daily smokers compared with $20 \%$ of the general population. ${ }^{3}$ Furthermore, patients with mental illness were 2.5 times more likely to be heavy smokers. ${ }^{3}$ Overall, patients with a severe mental illness had reduced life expectancies of 15 and 20 years in women and men, respectively, ${ }^{4}$ and a recent study found that one-third of the 15 lost life years in smokers with a severe mental disorder (SMD) may be attributed to smoking. ${ }^{2}$ Based on observational studies, successful smoking cessation has been shown to improve mental health ${ }^{5}$ and reduce mortality and morbidity in patients with psychiatric issues. ${ }^{2}{ }^{6}$ Most smoking cessation interventions combine behavioural and pharmacological support. A recent review on the efficacy of smoking cessation intervention in patients with a severe mental illness concluded that bupropion and varenicline appear to be as effective in populations with psychiatric issues as in the 
general public. ${ }^{7}$ However, the effectiveness of behavioural interventions alone remains unclear. ${ }^{7}$ Despite these findings, smoking is often ignored in inpatient psychiatry. ${ }^{8}$

In 2013, the National Institute for Health and Care Excellence published a guideline concerning smoking cessation for individuals requiring acute, maternity and mental health services, stating that smokers with a mental illness should be offered intensive smoking cessation support. ${ }^{9}$ The Gold Standard Programme (GSP) is an intensive face-to-face smoking cessation intervention consisting of 5-6 meetings. The programme has been shown to have a good effect on smoking cessation in other subpopulations, as well as for the general population, ${ }^{10-14}$ but its effectiveness in smokers with an SMD remains unknown.

The aim of this study was to compare the effectiveness of the GSP in smokers with and without a diagnosed SMD and to identify factors associated with successful quitting. We hypothesised that this vulnerable subgroup of smokers would be less likely to be continuously smoke-free after 6 months than smokers without a mental disorder.

\section{METHOD}

\section{Study design and setting}

We performed a register-based cohort study using data from two national Danish registers: the Smoking Cessation Database ${ }^{15}$ and the National Patient Register. ${ }^{16}{ }^{17}$ The Smoking Cessation Database was established to evaluate the effect of smoking cessation interventions offered throughout Denmark, and data has been prospectively collected since 2001. The database now includes $>111000$ smokers who received face-to-face assistance to quit smoking.

At birth or on immigration, all people in Denmark are assigned a unique personal 10-digit identification number known as a 'Central Person Register' (CPR) number which contains information on sex and date of birth of the individual. ${ }^{18}$ The CPR number is used as the unique identification number in the National Patient Register as well as in many other Danish registers, making it possible to link information relating to an individual. ${ }^{19}$

Since 2006, each smoker provided informed consent and was thereafter registered in the Smoking Cessation Database with their CPR number. The CPR number was used to control for smokers attending more than one intervention and to identify smokers diagnosed with mental disorder(s) using data from the National Patient Register. Since 1995, all contacts (inpatient or outpatient) with somatic and psychiatric wards of all hospitals in Denmark have been registered in the National Patient Register using the International Classification of Diseases, 10th edition. ${ }^{16} 17$

All smokers in Denmark, including smokers with a mental disorder, have access to smoking cessation interventions without referral and free of charge. Throughout the study period from 1 January 2006 to 31 December 2016, 302 smoking cessation clinics in different settings, such as hospitals, midwife interactions, municipal clinics, pharmacies, primary care facilities and other private institutions, reported data to the Smoking Cessation Database. ${ }^{15}$ Approximately $80 \%-90 \%$ of the face-to-face interventions in Denmark are registered in the Smoking Cessation Database, and are considered a representative sample. ${ }^{20}$

In Denmark, the prevalence of daily smokers $(\geq 15$ years) dropped from $25 \%$ in 2006 to $16 \%$ in $2016 .{ }^{21}$ This corresponds to a drop from 1100000 to 765000 smokers. Thus, the Smoking Cessation Database (SCDB) contains information on $6 \%-9 \%$ of the daily smokers in Denmark.

\section{Intervention}

GSP is the standard smoking cessation intervention in Denmark. ${ }^{15}$ The GSP comprises five meetings held either in groups (2 hours/session) or as an individual session (first session lasting $40 \mathrm{~min}$ and approximately $20 \mathrm{~min} /$ sessions thereafter) over a 6 -week period. The programme was presented by specially trained staff and was counselling-based with a clearly structured manual-based patient education programme. The quit date was planned between the second and the third meeting. Each smoker was offered individual counselling on nicotine replacement therapy or other medical support according to their level of dependence, as measured by the Fagerström test score. ${ }^{15} 22$ It was recommended (but not mandatory) after 3 months to offer a sixth meeting after 3 months focusing on relapse prevention. To follow-up on the effect of the intervention, patients registered in the Smoking Cessation Database were contacted by phone 6 months $( \pm 1$ month) after the planned quit date and asked about their smoking status. ${ }^{15}$ Because patients were reached by phone, the self-reported smoking status was not validated. ${ }^{15}$ The intervention has been previously described in detail. ${ }^{101415}$

\section{Participants}

The study cohort included 74121 smokers registered in the Smoking Cessation Database during the study period. If a smoker attended more than one intervention, only the latest intervention was included (7180 smokers (corresponding to $9.3 \%$ of all smokers) were registered more than once; 9523 interventions were not included). Smokers were not included in the study if they met any of the following criteria: younger than 18 years of age at the onset of the intervention (1146), no attendance at a GSP (16 077) or attendance at a smoking cessation clinic that predecided, on the administrative level, not to contact their participants for follow-up after 6 months (8496).

To identify smokers with a mental disorder(s), the remaining 38879 smokers in the Smoking Cessation Database were cross-referenced with data from the National Patient Register using CPR numbers. Psychiatric discharge diagnoses given before the onset of the smoking cessation intervention were extracted. All psychiatric diagnoses (Chapter V; Mental and behavioural disorders, F00-F99), except F17 (Mental and behavioural disorders due to use of tobacco) 
were initially linked to the smokers. Patients diagnosed with organic mental disorders (F0 chapter) or intellectual disabilities (F7 chapter) were not included in the study regardless of other psychiatric diagnoses. Smokers without any psychiatric diagnosis composed the control group. Patients were categorised based on the severity and occurrence of a specific SMD according to the following hierarchy: schizophrenia (F20), schizotypal disorder (F21), other psychoses (F22-F25, F28-29), manic episodes (F30), bipolar disorder (F31), depression (F32-F34), anxiety (F40-F41), obsessive-compulsive disorder (F42), post-traumatic stress disorder (F43.1), personality disorders (F60F69) and substance use disorder (SUD) (F1). To avoid representing a patient multiple times in the analyses, the most severe diagnosis as defined by the hierarchy above was considered the primary discharge diagnosis. Smokers without an SMD but with other diagnosed mental disorders were omitted from the primary outcome analysis. Thus, 38293 smokers with or without a mental disorder were included in this study (see flow chart in figure 1).

Patient and public involvement

This study is based on data from any smokers participating in smoking cessation interventions available to the public without referral and free of charge. Patients or public were not otherwise involved in this study.

\section{Outcome and other variables}

The primary outcome was self-reported continuous abstinence measured 6 months after quitting. Continuous abstinence was defined as not having smoked at all from the quit date to the 6 -month follow-up contact. ${ }^{15}$

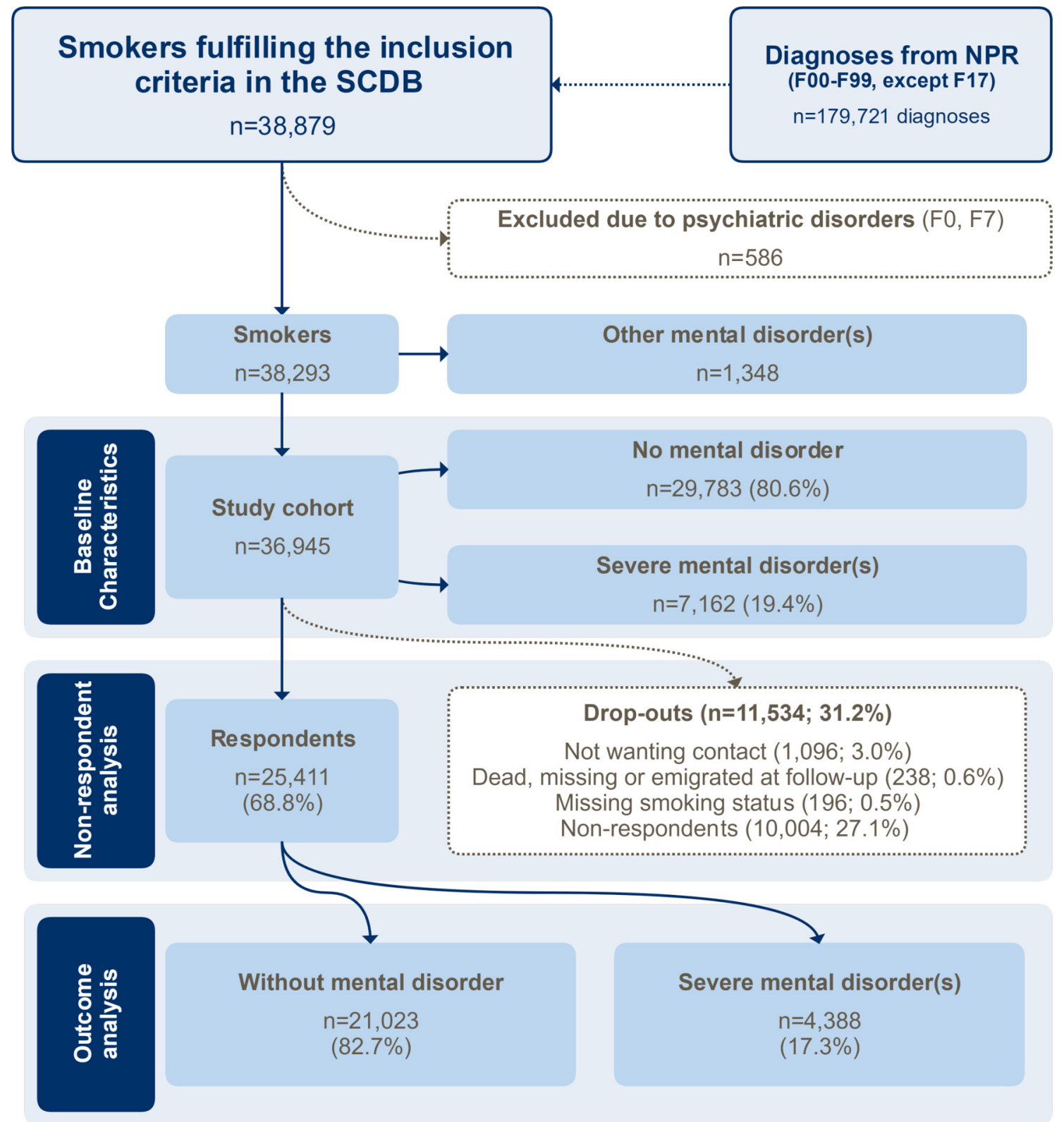

Figure 1 Flow chart of patient inclusion in the study. Smokers at least 18 years of age who attended a GSP between 1 January 2006 and 31 December 2016 were included in this study. A total of 11534 smokers were lost to follow-up, leaving 25411 smokers for inclusion in the outcome analyses. GSP, Gold Standard Programme; NPR, National Patient Register. 
For each smoker registered in the Smoking Cessation Database, data relating to sociodemographic characteristics, smoking history, intervention programme and follow-up information were collected. Age and smoking information were collected as continuous variables, whereas the remaining variables were categorical and grouped as shown in table 1 (and online supplementary appendix A). Confounders and predictors included in the statistical analyses are listed in table 1 .

Compliance with regard to meeting adherence was defined as attending at least $75 \%$ of the scheduled meetings as defined by the steering committee. ${ }^{23}$

Smokers were considered heavy smokers if they fulfilled one or more of three criteria: a $\geq 20$ pack-year smoking history, daily consumption of $\geq 20$ cigarettes or a nicotine dependency $\geq 7$ points according to the Fagerström test score. ${ }^{1322}$ Smokers were considered disadvantaged if they fulfilled at least one of two criteria: unemployment (receiving unemployment benefits) or low level of education (no education except for elementary school or short work-related courses). ${ }^{14}$

\section{Data access and cleaning}

We had full access to data relating to all smokers recorded in the Smoking Cessation Database from 2006 to 2016. Throughout this period, smokers were registered using their individual CPR number. All CPR numbers were checked for validity using official validation rules. Invalid numbers were checked in the Civil Registration System and corrected if possible, and age and sex were corrected accordingly. If correction was not possible, the smokers were excluded from the database. In this study, 484 of 67339 smokers (corresponding to $0.7 \%$ ) were omitted from the database due to an invalid CPR number.

The online registration application of the Smoking Cessation Database supplies automatic data validation rules to ensure that only valid dates and required data are entered. In addition to these rules, daily consumption of tobacco was manually checked. Daily consumption of more than $100 \mathrm{~g}$ was considered unlikely, and these data were recoded to 'missing'. Likewise, years of smoking was recoded to 'missing' if the years of smoking were greater than the age of the smoker.

\section{Statistical analysis}

After performing initial analyses on the selected predictors (from online supplementary appendix A) adjusted for sex and age, a multivariable mixed-effect model was fitted to test for differences in continuous abstinence. The predictors were chosen based on the initial analysis and established knowledge. ${ }^{24}$ The multivariable analysis was performed by entering all the predictors together (see table 1). In addition, the analysis was adjusted for hierarchical clustering using the different smoking cessation clinics as the 1st level cluster. The analysis was repeated for relevant subgroups of mental disorders. To examine whether the time span from diagnosis to participation in a GSP was related to continuous abstinence, a separate univariate logistical regression was conducted. The span was calculated as time from initial diagnosis of an SMD to the start of the GSP.

Data were reported according to the REporting of studies Conducted using Observational Routinely collected health Data statement. ${ }^{25}$ Patients with missing values were excluded from the analyses. The results were presented as ORs and 95\% CIs. Non-respondent analysis was performed using a $\chi^{2}$ test to compare respondents to non-respondents. A similar analysis was performed to compare the smokers who were intentionally not followed up to the included smokers. A two-sided $p$ value $<0.05$ was considered statistically significant. All statistical calculations were performed with Stata/IC V.15.0 (StataCorp).

\section{RESULTS}

In this cohort study, 38293 smokers were linked to the National Patient Register to identify smokers with a mental disorder. While 25411 smokers with or without an SMD were included in the main analysis, $31 \%$ were lost to follow-up (29\% among smokers without a mental illness and 39\% among smokers with an SMD) (see figure 1). Non-respondent analyses revealed that except for living with a smoker, all other tested predictors significantly differed between the respondents and the non-respondents. The largest difference (14 percentage points) observed was in participant compliance with the respondents showing more compliance with the programme. Smokers with an SMD were more likely to withdraw from the study (schizophrenia spectrum, 43.2\%; affective disorders, $38.9 \%$; anxiety, $36.1 \%$; personality disorders, $38.7 \%$; SUD, $36.7 \%$ ) as were women, disadvantaged smokers and smokers who attended individual counselling; however, heavy smokers and smokers who were recommended to quit by healthcare staff were more likely to be respondents.

The percentage of individuals who successfully quit was $29.4 \%$ and $38 \%$ for smokers with an SMD and the control group, respectively (see table 2 ).

The characteristics of smokers without a mental disorder and smokers with an SMD differed considerably (see table 1 , and online supplementary appendix A). In particular, the proportion of smokers with an SMD was highest among young smokers and gradually decreased as age increased. In addition, smokers with an SMD were more likely to be heavy smokers, non-compliant and recommended to stop smoking by healthcare staff and were more often disadvantaged; all these factors were predictors of relapsing within 6 months of completing the GSP. In addition, smokers with an SMD were less likely to live with other smokers and more likely to attend individual interventions, both of which were predictors of a successful outcome. Approximately half the smokers in both groups (51\% of smokers with an SMD and $45 \%$ without an SMD) were offered pharmaceutical support (eg, nicotine replacement therapy, varenicline or bupropion, free of charge). 
Table 1 Characteristics of the study population and predictors for continuous abstinence

\section{Characteristics}

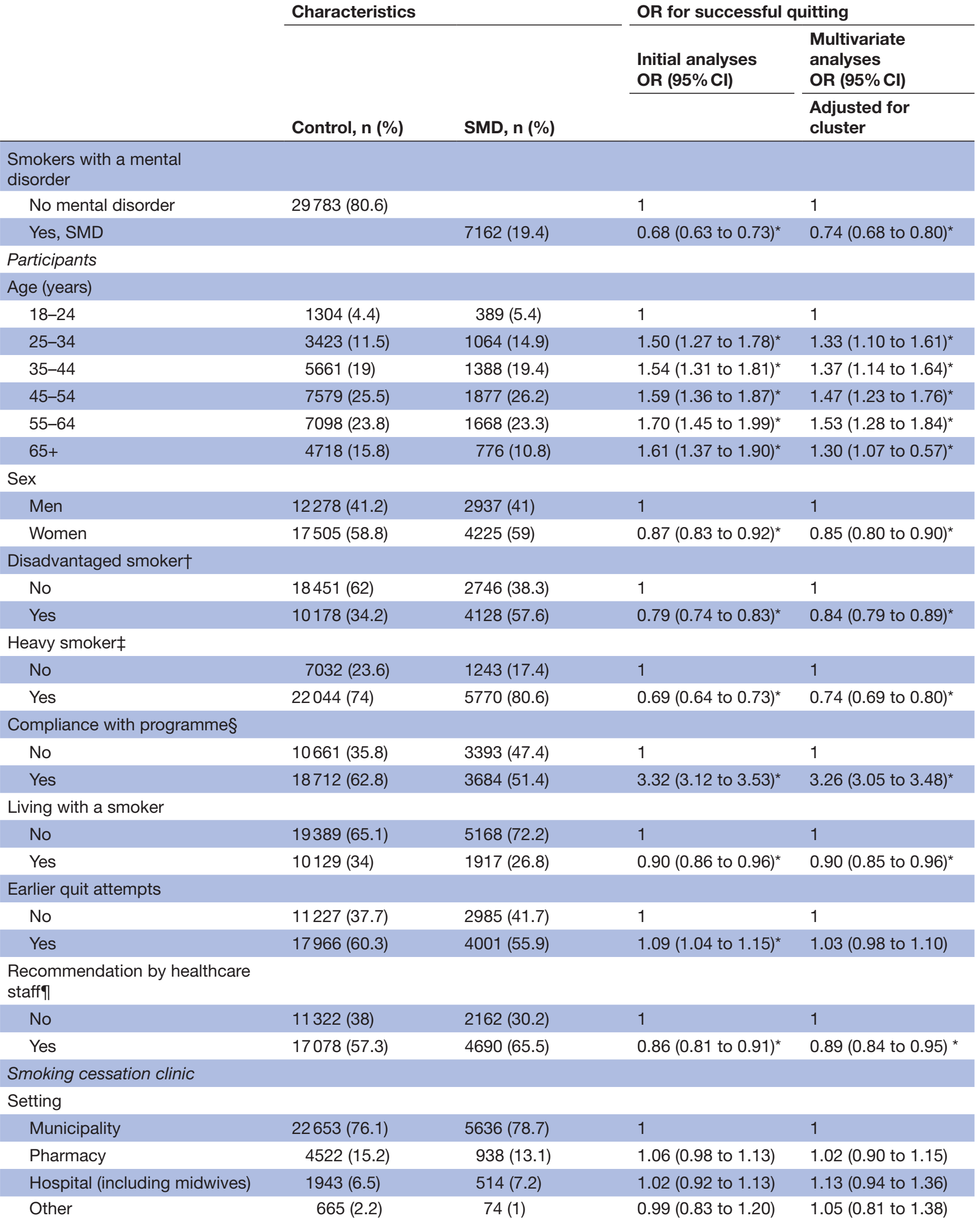


Table 1 Continued

\begin{tabular}{|c|c|c|c|c|}
\hline & Characteristics & & OR for successful & ditting \\
\hline & & & $\begin{array}{l}\text { Initial analyses } \\
\text { OR }(95 \% \mathrm{Cl})\end{array}$ & $\begin{array}{l}\text { Multivariate } \\
\text { analyses } \\
\text { OR }(95 \% \mathrm{CI})\end{array}$ \\
\hline & Control, n (\%) & SMD, n (\%) & & $\begin{array}{l}\text { Adjusted for } \\
\text { cluster }\end{array}$ \\
\hline $\begin{array}{l}\text { Smoking cessation } \\
\text { intervention }\end{array}$ & & & & \\
\hline Programme format & & & & \\
\hline Group & $24925(83.7)$ & $5347(74.7)$ & 1 & 1 \\
\hline Individual & 4858 (16.3) & $1813(25.3)$ & $1.30(1.21 \text { to } 1.39)^{\star}$ & $1.17(1.07 \text { to } 1.28)^{\star}$ \\
\hline Cluster & & & & \\
\hline Smoking cessation clinic & & & & $0.05(0.03 \text { to } 0.08)^{\star}$ \\
\hline $\begin{array}{l}\text { The initial analyses were adju } \\
\text { of intervention and hierarchic } \\
\text { The results were reported as } \\
{ }^{*} \mathrm{P} \text { value }<0.05 \text { (considered st } \\
\text { †Disadvantaged: } \leq 12 \text { years o } \\
\text { fHeavy smoker: } \geq 20 \text { pack ye } \\
\text { §Compliance: attended } \geq 75 \% \\
\text { १Healthcare staff: doctors, nu } \\
\text { SMD, severe mental disorder. }\end{array}$ & $\begin{array}{l}\text { and age only. In ad } \\
\text { (smoking cessatior } \\
\% \text { Cls. } \\
\text { gnificant). } \\
\text { t/or unemployed. } \\
\text { öm score of } \geq 7 \text { poir } \\
\text { ned meeting sessio } \\
\text { s' assistants, midwi }\end{array}$ & $\begin{array}{l}\text { to the listed } p \\
\text { ). } \\
\text { d/or daily consu } \\
\text { tc. }\end{array}$ & $\begin{array}{l}\text { he multivariable model } \\
\geq 20 \text { cigarettes. }\end{array}$ & as adjusted for the year \\
\hline
\end{tabular}

\section{Primary outcome: smoking cessation at $\mathbf{6}$ months}

After adjusting for clustering and confounding factors, we found that smokers with an SMD were significantly less likely to maintain continuous abstinence 6 months after attending a GSP (OR 0.74, 95\% CI 0.68 to 0.80 ; $\mathrm{p}<0.001$ ). The time span between the primary discharge diagnosis and the start of the GSP showed a small but statistically significant association with continuous abstinence (OR $1.02,95 \%$ CI 1.00 to $1.03 ; \mathrm{p}=0.013$ ). We identified associations between a higher risk of relapse and female gender (OR $0.85,95 \% \mathrm{CI} 0.80$ to 0.90 ), disadvantaged status (OR $0.84,95 \% \mathrm{CI} 0.79$ to 0.89 ), heavy smoking (OR $0.74,95 \%$ CI 0.69 to 0.80 ) and recommendations to quit by healthcare staff (OR $0.89,95 \%$ CI 0.84 to 0.95 ). Factors associated with successful quitting were older age (OR $1.30,95 \%$ CI 1.07 to 1.57 ) compliance with the GSP (OR 3.26, 95\% CI 3.05 to 3.48 ) and attendance of an individual intervention (OR 1.17 , 95\% CI 1.07 to 1.28 ).

The proportion of successful quitters was $38 \%$ in the control group versus $30 \%$ in patients with any mental disorder (see table 2). The quit rates among the SMD subgroups differed by approximately 7 percentage points;

Table 2 Crude quit rates and associations of successful quitting according to smoker subgroups stratified by the severity of the mental disorder

\begin{tabular}{|c|c|c|c|c|}
\hline & & Crude quit rate & $\begin{array}{l}\text { Multivariate analyses } \\
\text { OR }(95 \% \mathrm{Cl})\end{array}$ & \\
\hline Diagnoses (ICD-10) & $\mathbf{n}$ & $\%$ & Adjusted for cluster & $P$ values \\
\hline Control: no psychiatric diagnoses & 21044 & 38 & 1 & \\
\hline Any mental disorder & 5306 & 30 & $0.75(0.70 \text { to } 0.81)^{\star}$ & $<0.000$ \\
\hline Severe mental disorder & 4404 & 29.4 & $0.74(0.68 \text { to } 0.80)^{*}$ & $<0.000$ \\
\hline Schizophrenia spectrum (F20-F29) & 692 & 25.7 & $0.61(0.50 \text { to } 0.74)^{*}$ & $<0.000$ \\
\hline Affective disorders (F30-F34) & 1742 & 31 & $0.80(0.71 \text { to } 0.90)^{*}$ & $<0.000$ \\
\hline Anxiety (F40-F42, F43.1) & 548 & 31.9 & $0.86(0.70$ to 1.06$)$ & 0.156 \\
\hline Personality disorders (F60-69) & 294 & 26.9 & $0.62(0.46 \text { to } 0.83)^{\star}$ & 0.001 \\
\hline $\begin{array}{l}\text { Substance use disorder (F10-16, } \\
\text { F18-F19) }\end{array}$ & 1128 & 28.6 & $0.68(0.59 \text { to } 0.79)^{\star}$ & $<0.000$ \\
\hline Other & 902 & 32.9 & $0.83(0.71 \text { to } 0.98)^{*}$ & 0.027 \\
\hline
\end{tabular}

${ }^{*} \mathrm{P}<0.05$.

ICD-10, International Classification of Diseases, 10th edition. 


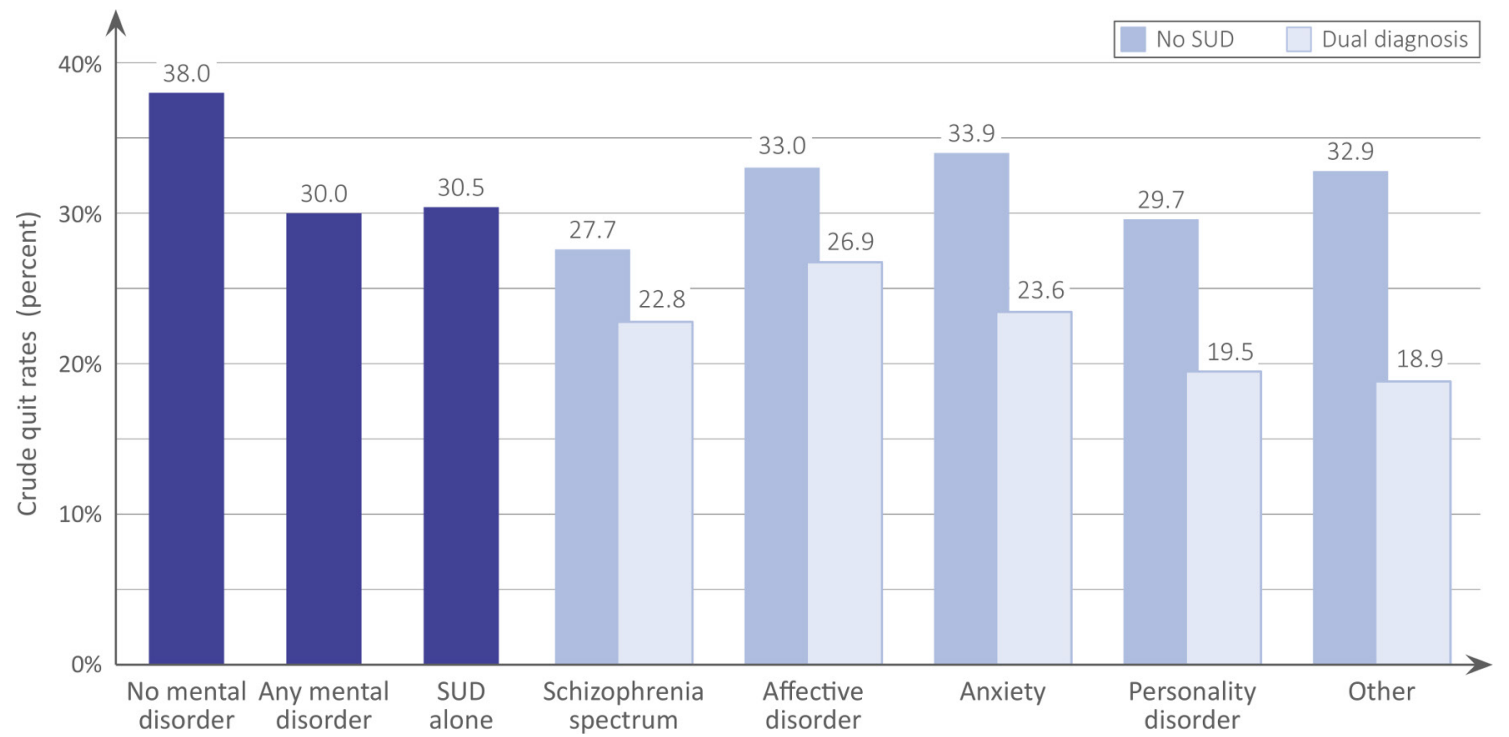

Figure 2 Crude quit rates according to the specified mental disorder with or without SUD. SUD, substance use disorder.

however, for patients within the schizophrenia spectrum, which was the least successful group, the proportion of successful quitters was $25.7 \%$. All the subgroups, except anxiety, were significantly less likely to stay continuously abstinent after 6 months than the control group.

We examined the occurrence of dual diagnoses, defined as having SUD in addition to any other mental disorder(s), and the effect of these diagnoses on smoking cessation for subgroups of smokers with a mental disorder. The occurrence of dual diagnoses differed between $17 \%$ and $41 \%$ in the subgroups. Moreover, the proportion of successful quitters was lower in patients with dual diagnoses $(18.9 \%-$ $26.9 \%)$ than in patients without SUD (27.7\%-33.9\%), corresponding to a reduction in successful outcomes by $18 \%-43 \%$. This should be compared with a quit rate of $30.5 \%$ among patients with SUD alone (see figure 2).

\section{Intentional lack of follow-up}

The characteristics shown in table 1 were compared between the included smokers and smokers who were intentionally not followed up due to an administrative decision in the smoking cessation clinic. The analyses showed that there were statistically significant differences between the two groups with regard to mental diagnoses, heavy smoking, compliance, living with a smoker, earlier quit attempts, setting, programme format and year of intervention. The differences were most pronounced in relation to arena (22 percentage points), where smokers attending an intervention in a municipal clinic were most likely to receive a follow-up call. The year of intervention (9 percentage points) revealed that smokers were less likely to receive follow-up before 2010. All other factors differed by fewer than 5 percentage points, and smokers with a mental disorder were more likely to receive follow-up than heavy smokers, non-compliant smokers, smokers not living with another smoker and smokers attending a group intervention.

\section{DISCUSSION}

Overall, 28\% of the smokers with an SMD stayed continuously smoke-free for at least 6 months after undergoing a GSP intervention compared with $38 \%$ without an SMD. This was in agreement with our main hypothesis. Compliance was by far the most important predictor of a successful outcome. Dual diagnoses of SMDs lowered the proportion of successful quitters to $19 \%-27 \%$, depending on the diagnoses.

Smokers with an SMD were as likely to want to quit smoking as the general population, ${ }^{3}$ but the evidence of smoking cessation intervention is sparse among this group. A recent review concluded that although bupropion and varenicline appear to be effective among smokers with an SMD, the efficacy of nicotine replacement therapy and behavioural treatment is still unclear. ${ }^{7}$ Another review illuminating the effect of specialised advice to smokers with an SMD revealed only one ongoing trial investigating this topic. $^{26}$

Promising results were presented in a randomised trial on treating tobacco dependence among inpatients at a psychiatric ward with a complete smoking ban. Prochaska et al observed a point prevalence of $14 \%$ in smokers undergoing an intervention combining behavioural treatment and nicotine patches at 6 months after intervention in contrast to $7 \%$ in the usual care control group. ${ }^{8}$ Even unmotivated patients were able to successfully quit, and the long-term results after 18 months were positive. ${ }^{8}$

In our study, $28 \%$ of the participants with an SMD continued to abstain after 6 months. Smokers diagnosed within the schizophrenia spectrum benefited the least from the GSP. Although meta-analyses have also shown a lower effect in this group, ${ }^{27}$ smokers with depression showed higher quit rates. ${ }^{28} \mathrm{~A}$ review reported that only two small studies have been published concerning smokers with bipolar disorders, ${ }^{29}$ and both trials had difficulties recruiting smokers within this subgroup. In our 
subgroup analysis, smokers with anxiety (F4 Chapter) were also likely to have been slightly underpowered which was also the case for the subgroup of smokers classified as 'other diagnoses'.

The GSP is a package consisting of several elements, including an extensive patient education programme, individual counselling and pharmaceutical support. ${ }^{1015} \mathrm{In}$ our study, it was not possible to pinpoint which elements were the most important or whether some of the elements were unnecessary for different groups of smokers. In addition to the different mental diagnoses, variations in the severity of mental disease may impact the quit rates. On the one hand, one could expect that smokers with an SMD are more likely to be successful in their quit attempt when they are well treated and close to discharge. On the other hand, a hospital stay in completely smoke-free surroundings has been shown to be supportive-for SMD smokers as well. ${ }^{8}$

Dual diagnoses appear to have a great impact on the ability to quit smoking, and it would be relevant to evaluate combined interventions for both smoking and substance abuse. Although the evidence is also sparse, smoking cessation intervention has been shown to be effective for smokers in short-term substance abuse treatment. ${ }^{30}$

This study has strengths and limitations. Because the aim of this study was in line with the purposes of the Smoking Cessation Database, we considered the implications of using these routinely collected health data to be minimal. However, one potential weakness was that participants with an SMD were included independent of the time span from diagnoses to the intervention onset. Surprisingly, we found only a small significant association between time span and continuous abstinence, and this association should be investigated in more detail in future intervention studies. Using the National Patient Register, we identified only smokers with a mental disorder severe enough to justify hospitalisation (inpatient or outpatient). There might be patients in the Smoking Cessation Database with mental disorders who did not receive hospital care, but we must assume that their mental disorders are much less severe. The proportion of participants lost to follow-up was moderate $(31 \%)$. In this study, we only included respondents in the final analysis, thus assuming that the quit rates among non-respondents were similar to the quit rates estimated in this study. Because the non-respondent analysis showed a higher proportion of non-compliant participants among the non-respondents, it is likely that the quit rates in this study are overestimated.

One strength of this study was the large nationwide cohort and the inclusion of all settings (municipalities, hospitals, pharmacies, etc) where smoking cessation interventions in Denmark were conducted. Data from both registries used in this study provide a high degree of completeness and precision, and the amount of missing data was very low. ${ }^{1517}$ We were unable to identify possible misclassifications, but the occurrence of these was expected to be very low. ${ }^{15} 17$

The use of continuous abstinence instead of point prevalence was a strength, but self-reporting without biomarker validation was a limitation ${ }^{31}$ that might have introduced reporting bias. ${ }^{32}$ Contrary to the logical presumption that the use of this outcome would prove more precise, a Canadian study showed no significant difference between self-reported smoking status and urinary cotinine levels. ${ }^{33}$ The use of carbon monoxide tests to validate smoking status showed that validation increased the detection of smokers with short-term and long-term quit rates by only 6 and 3 percentage points, respectively. ${ }^{34}{ }^{35}$ Similar results were observed in a Danish study where self-reported and validated abstinence differed by $3-4$ percentage points. ${ }^{36}$

Due to differences in national and cultural traditions, smoking habits, socioeconomic conditions and the diagnosis of SMDs, the external validity of these results is limited and should be considered carefully before extrapolating to other developed countries.

Overall, it is important for smokers with a mental disorder to be offered clinical help to quit smoking due to the many positive effects of smoking cessation on both physical and mental health. ${ }^{5}$ However, the evidence on how to best help this group of smokers is sparse. Randomised controlled trials have shown that smoking cessation interventions can be effective, and this study reports that it is feasible to help a clinically relevant part of this vulnerable subgroup of smokers; however, these individuals have a lower quit rate than smokers without an SMD. More evidence is needed concerning the treatment of competing addictions and dual diagnoses.

\section{CONCLUSION}

Only $28 \%$ of the smokers with an SMD successfully quit smoking which is significantly lower than the rate observed among smokers without an SMD (38\%). The lowest quit rates were observed among patients with dual diagnoses, and the most important predictor of successful quitting was compliance.

Acknowledgements All smokers are acknowledged for agreeing to be registered in the Smoking Cessation Database, as are all staff at the participating Smoking Cessation Clinics and the staff at the National Secretariat. The Danish Ministry of Health, the Danish Health Authority, and Bispebjerg and Frederiksberg Hospital are acknowledged for financing the Danish Smoking Cessation Database.

Contributors MR, MK and HT contributed to the study conception and design. MR and $\mathrm{HT}$ headed the data acquisition. MR contributed to the data analysis. MR, MK, $\mathrm{JK}, \mathrm{MN}$ and $\mathrm{HT}$ contributed to the data interpretation. MR drafted the manuscript, and MK, JK, MN and HT revised it critically for important intellectual content. All the authors gave final approval of the version to be published. MR is the guarantor.

Funding The authors have not declared a specific grant for this research from any funding agency in the public, commercial or not-for-profit sectors.

Competing interests None declared.

Patient consent Not required.

Ethics approval This project was approved by the Danish Data Protection Agency (2014-41-3370/2010-41-5463/2000-54-0013) and was registered with the National Committee on Health Research Ethics (H-C-FSP-2010-049). 
Provenance and peer review Not commissioned; externally peer reviewed.

Data sharing statement The protocol, anonymised data and statistical codes are available from the corresponding author.

Open access This is an open access article distributed in accordance with the Creative Commons Attribution Non Commercial (CC BY-NC 4.0) license, which permits others to distribute, remix, adapt, build upon this work non-commercially, and license their derivative works on different terms, provided the original work is properly cited and the use is non-commercial. See: http://creativecommons.org/ licenses/by-nc/4.0/

(C) Article author(s) (or their employer(s) unless otherwise stated in the text of the article) 2018. All rights reserved. No commercial use is permitted unless otherwise expressly granted.

\section{REFERENCES}

1. Lasser K, Boyd JW, Woolhandler S, et al. Smoking and mental illness. JAMA 2000;284:2606.

2. Tam J, Warner KE, Meza R. Smoking and the reduced life expectancy of individuals with serious mental illness. Am J Prev Med 2016;51:958-66.

3. Nordentoft M, Krogh J, Lange P, et al. Psykisk sygdom og ændringer i livsstil. 2015 www.Vidensraad.dk

4. Wahlbeck K, Westman J, Nordentoft M, et al. Outcomes of Nordic mental health systems: life expectancy of patients with mental disorders. Br J Psychiatry 2011;199:453-8.

5. Taylor G, McNeill A, Girling A, et al. Change in mental health after smoking cessation: systematic review and meta-analysis. BMJ 2014;348:g1151.

6. Bobes J, Arango C, Garcia-Garcia M, et al. Healthy lifestyle habits and 10-year cardiovascular risk in schizophrenia spectrum disorders: an analysis of the impact of smoking tobacco in the CLAMORS schizophrenia cohort. Schizophr Res 2010;119:101-9.

7. Peckham E, Brabyn S, Cook L, et al. Smoking cessation in severe mental ill health: what works? an updated systematic review and meta-analysis. BMC Psychiatry 2017;17:252.

8. Prochaska JJ, Hall SE, Delucchi K, et al. Efficacy of initiating tobacco dependence treatment in inpatient psychiatry: a randomized controlled trial. Am J Public Health 2014;104:1557-65.

9. NICE National Institute for Health and Care Excellence. Public health guideline: smoking: acute, maternity and mental health services (PH48). https://www.nice.org.uk/guidance/ph48/chapter/ 1-Recommendations\#recommendation-3-provide-intensive-supportfor-people-using-acute-and-mental-health-services (cited 7 Sep 2017).

10. Rasmussen M, Fernández E, Tønnesen H. Effectiveness of the gold standard programme compared with other smoking cessation interventions in Denmark: a cohort study. BMJ Open 2017;7:e013553.

11. Kehlet M, Schroeder TV, Tønnesen $\mathrm{H}$. The gold standard program for smoking cessation is effective for participants over 60 years of age. Int J Environ Res Public Health 2015;12:2574-87.

12. Rasmussen M, Heitmann BL, Tønnesen H. Effectiveness of the gold standard programmes (GSP) for smoking cessation in pregnant and non-pregnant women. Int $J$ Environ Res Public Health 2013;10:3653-66.

13. Neumann T, Rasmussen M, Heitmann BL, et al. Gold standard program for heavy smokers in a real-life setting. Int $J$ Environ Res Public Health 2013;10:4186-99.

14. Neumann T, Rasmussen M, Ghith N, et al. The Gold Standard Programme: smoking cessation interventions for disadvantaged smokers are effective in a real-life setting. Tob Control 2013;22:e9.
15. Rasmussen M, Tønnesen $\mathrm{H}$. The Danish smoking cessation database. Clinical Health Promotion - Research and Best Practice 2016;6:36-41.

16. Lynge E, Sandegaard JL, Rebolj M. The Danish national patient register. Scand J Public Health 2011;39(7 Suppl):30-3.

17. Schmidt M, Schmidt SA, Sandegaard JL, et al. The Danish national patient registry: a review of content, data quality, and research potential. Clin Epidemiol 2015;7:449.

18. Pedersen CB. The Danish civil registration system. Scand J Public Health 2011;39(7 Suppl):22-5.

19. Thygesen LC, Daasnes C, Thaulow I, et al. Introduction to Danish (nationwide) registers on health and social issues: structure, access, legislation, and archiving. Scand J Public Health 2011;39(7 Suppl):12-16.

20. Rasmussen $\mathrm{M}, \mathrm{Ammari} \mathrm{ABH}$, Pedersen $\mathrm{B}$, et al. Smoking cessation intervention activities and outcome before, during and after the national Healthcare Reform in Denmark. Clin Heal Promot 2012;2:26-35.

21. Sundhedsstyrelsen. Danish smoking habits [Danskernes rygevaner]. Copenhagen. 2018 https://www.sst.dk/da/sundhed-oglivsstil/tobak/udgivelser/danskernes-rygevaner (cited 18 Feb 2018).

22. Heatherton TF, Kozlowski LT, Frecker RC, et al. The Fagerström test for nicotine dependence: a revision of the fagerström tolerance questionnaire. Br J Addict 1991;86:1119-27.

23. Ghith $\mathrm{N}$, Ammari ABH, Rasmussen M, et al. Impact of compliance on quit rates in a smoking cessation intervention: population study in Denmark. Clin Heal Promot 2012;2:111-9.

24. Ditre JW, Zale EL, Brandon TH. Patterns and predictors of smoking cessation. In: Loddenkemper R, Kreuter M, eds. The tobacco epidemic. 2nd edn: Karger, 2015:210-8.

25. Benchimol El, Smeeth L, Guttmann A, et al. The reporting of studies conducted using observational routinely-collected health data (RECORD) statement. PLoS Med 2015;12:e1001885.

26. Khanna P, Clifton AV, Banks D, et al. Smoking cessation advice for people with serious mental illness. Cochrane Database Syst Rev 2016;1:CD009704.

27. Tsoi DT, Porwal M, Webster AC. Interventions for smoking cessation and reduction in individuals with schizophrenia. Cochrane Database Syst Rev 2013;1:CD007253.

28. Gierisch JM, Bastian LA, Calhoun PS, et al. Smoking cessation interventions for patients with depression: a systematic review and meta-analysis. J Gen Intern Med 2012;27:351-60.

29. George TP, Wu BS, Weinberger AH. A review of smoking cessation in bipolar disorder: implications for future research. J Dual Diagn 2012;8:126-30.

30. Prochaska JJ, Delucchi K, Hall SM. A meta-analysis of smoking cessation interventions with individuals in substance abuse treatment or recovery. J Consult Clin Psychol 2004;72:1144-56.

31. West R, Hajek P, Stead L, et al. Outcome criteria in smoking cessation trials: proposal for a common standard. Addiction 2005;100:299-303.

32. Fendrich M, Mackesy-Amiti ME, Johnson TP, et al. Tobacco-reporting validity in an epidemiological drug-use survey. Addict Behav 2005;30:175-81.

33. Wong SL, Shields M, Leatherdale S, et al. Assessment of validity of self-reported smoking status: Statistics Canada, 2012. Catalogue no. 82-003-XPE; Health Reports.

34. Ferguson J, Bauld L, Chesterman J, et al. The English smoking treatment services: one-year outcomes. Addiction 2005;100(Suppl. 2):59-69.

35. Judge K, Bauld L, Chesterman J, et al. The English smoking treatment services: short-term outcomes. Addiction 2005;100(Suppl 2):46-58.

36. Pisinger C, Vestbo J, Borch-Johnsen $\mathrm{K}$, et al. It is possible to help smokers in early motivational stages to quit. The Inter99 study. Prev Med 2005;40:278-84. 